\title{
Differential Expression of Somatostatin Receptor Subtypes in Brain
}

\author{
Christopher D. Breder, ${ }^{1}$ Yuichiro Yamada,, ${ }^{3, a}$ Kazuki Yasuda, ${ }^{3}$ Susumu Seino,, ${ }^{4,5, b}$ Clifford B. Saper, ${ }^{1,2, c}$ and \\ Graeme I. Bell ${ }^{3,4,5}$ \\ ${ }^{1}$ Committee on Neurobiology and the Brain Research Institute, Departments of Pharmacological and Physiological \\ Sciences and Neurology, ${ }^{3}$ Department of Biochemistry, ${ }^{4}$ Department of Medicine, and ${ }^{5}$ Howard Hughes Medical Institute, \\ University of Chicago, Chicago, Illinois 60637
}

\begin{abstract}
The tetradecapeptide somatostatin has been implicated as an important regulator of neuronal and neuroendocrine function in the CNS. The cellular actions of somatostatin are mediated by specific receptors. The genes encoding two different somatostatin receptors (SSTRs) have been isolated and characterized, and RNA blotting studies have shown that both SSTR1 and SSTR2 are expressed in the brain. In order to gain a better understanding of the functions of somatostatin in the CNS, the distribution of SSTR1 and SSTR2 mRNAs was determined using the technique of in situ hybridization. SSTR1 mRNA was present throughout the mouse brain, particularly in the supra- and infragranular layers of the cortex, the amygdala, hippocampus, bed nucleus of the stria terminalis, substantia innominata, hypothalamus, pretectum, substantia nigra, parabrachial nucleus, and nucleus of the solitary tract. SSTR2 mRNA was primarily observed in the infragranular layers of the cortex, the amygdala, claustrum, endopiriform nucleus, arcuate and paraventricular nuclei of the hypothalamus, and medial habenular nucleus. Several regions of the brain reported to contain dense somatostatin-like immunoreactive terminal fields and receptor binding sites were devoid of both SSTR1 and SSTR2 mRNA, suggesting the existence of additional SSTR subtypes.
\end{abstract}

Somatostatin (SST), the somatotropin-release inhibitory factor, is a tetradecapeptide that was first identified in extracts of ovine hypothalamus by the inhibition of secretion of growth hormone (GH) from pituitary cell cultures (Brazeau et al., 1973). Subsequent studies have revealed multiple forms of this peptide in brain (Benoit et al., 1982) and have demonstrated the presence of SST-like immunoreactivity in neurons, nerve fibers, and presumptive terminal fields throughout the brain (Johansson et al., 1984; Vincent et al., 1985; Shimada and Ishikawa, 1989). Phys-

Received Feb. 21, 1992; revised Apr. 30, 1992; accepted May 5, 1992.

This work was supported by U.S. Public Health Service Grants NS-22835, HD. 07009, DK-20595, and DK-42086; Grants-in-Aid 91011120 from the American Heart Association; and the Brain Research Foundation, William D. Mabie Research Fund, and the Howard Hughes Medical Institute. K.Y. was supported by a Mentor-based fellowship from the American Diabetes Association. We thank Q. Ha and C. Hazuka for excellent technical assistance, and D. Simmons and L. Swanson for their technical advice.

Correspondence should be addressed to Dr. Graeme Bell, Howard Hughes Medical Institute, University of Chicago, 5841 South Maryland Avenue, MC1028, Chicago, IL 60637.

aPresent address: Second Department of Mcdicinc, Kyoto University School of Medicine, Kyoto 606, Japan.

'Present address: Division of Molecular Medicine, Center for Neurobiology and Molecular Immunology Chiba School of Medicine, Chiba 280, Japan.

'Present address: Department of Neurology, Beth Israel Hospital, Boston, MA. Copyright (C) 1992 Society for Neuroscience $0270-6474 / 92 / 123920-15 \$ 05.00 / 0$ iological studies (e.g., Wang et al., 1989) and the broad distribution of SST in the CNS suggest that SST may regulate many aspects of CNS function including neuroendocrine control (Lumpkin et al., 1981; Murakami et al., 1987; Horvath et al., 1989), autonomic function (Cunningham and Sawchenko, 1989; Nabekura et al., 1989; Rettig et al., 1989), nociception (Shimada and Ishikawa, 1989), appetitive behavior (Lin et al., 1987), and arousal (Danguir, 1986). SST has also been implicated in neuronal development (Kimura, 1989; Villar et al., 1989; Kentroti and Vernadakis, 1990), and altered levels and distribution of SST-like immunoreactivity have been noted in neuronal degenerative states such as Alzheimer's disease (Dawbarn et al., 1986; Unger et al., 1988) and Huntington's disease (Marshall and Landis, 1985).

The cellular actions of SST are mediated by specific highaffinity receptors (Srikant and Patel, 1981). The distribution of these receptors in the rat brain has been mapped by receptorbinding autoradiography using radiolabeled SST-14 and -28 as well as SST analogs such as CGP-23996 and MK-678 (Leroux et al., 1985; Uhl et al., 1985; Martin et al., 1991). These studies have shown differences in the pattern and levels of binding of these peptides in the brain, implying that the actions of SST may be mediated by a family of receptors, an idea supported by binding and physiological studies using SST-14 and its analogs (Wang et al., 1989). In addition, biochemical studies have identified a number of SST-binding proteins of various sizes from about 27 to $90 \mathrm{kDa}$ that can be labeled by cross-linking with SST and its analogs (Thermos et al., 1989; Patel et al., 1990). However, until recently it was not clear whether these proteins represented distinct receptors.

We have recently cloned and characterized the genes for two new members of the family of receptors with a seven-transmembrane segment that bind [ $\left.{ }^{125} \mathrm{I}-\mathrm{Tyr}^{11}\right]$-SST-14 specifically and with high affinity (Yamada et al., 1992). We termed these two SST receptor (SSTR) isoforms SSTR1 and SSTR2. Although SSTR1 and SSTR2 bind SST-14 with a similar affinity, their sequences are quite divergent and there is only $49 \%$ amino acid identity and $64 \%$ similarity between them. RNA blotting studies using human SSTR1 and SSTR2 probes revealed high levels of SSTR 1 mRNA in the human gastrointestinal tract including small intestine and stomach and high levels of SSTR2 mRNA in the brain and kidney. RNA blotting studies with the mouse probes have showed that both SSTR 1 and SSTR 2 mRNAs were present in the adult mouse brain. Using in situ hybridization, we have determined the anatomical pattern of expression of transcripts of these two receptors in the adult mouse brain. These studies revealed distinct but overlapping patterns of expression 
of each isoform in this tissue. In addition, the absence of noticeable hybridization in certain regions of the brain where previous receptor-binding autoradiography studies showed SST binding suggests that one or more additional SSTR isoform may be expressed in the mouse CNS.

\section{Materials and Methods}

General methods. Standard methods were carried out as previously described (Sambrook et al., 1989; Yamada et al., 1992). For Northern blotting, $20 \mu \mathrm{g}$ of total adult mouse brain RNA was denatured with glyoxal, electrophoresed in a $1 \%$ agarose gel and blotted using capillary action to a Hybond-N nylon membrane (Amersham, Arlington Heights, IL). The membrane was hybridized with nick-translated ${ }^{32} \mathrm{P}$-labeled inserts from the mouse SSTR 1 and SSTR2 probes described below.

Mouse SSTRI and SSTR 2 CDNA probes. The mouse SSTR1 probe was a 413 base pair (bp) BanII-AccI fragment of the gene that encodes amino acids $214-352$, and the mouse SSTR 2 probe was a 458 bp BstEII$X b a I$ fragment of the gene that encodes amino acids 254-369, the stop codon, and 107 nucleotides of the 3'-flanking/untranslated region; the sequences of the mouse SSTR1 and SSTR2 genes are in the GenBank database with accession numbers M81831 and M81832, respectively. There is $54 \%$ overall nucleotide sequence identity between the mouse SSTR 1 and SSTR2 sequences in the region of homology between these probes; the longest stretch of identity is 15 nucleotides. We examined the Northern blot for evidence of cross-hybridization with these probes using moderately stringent hybridization and washing conditions [hybridization: $5 \times$ saline-sodium citrate (SSC), $50 \%$ formamide, $20 \mathrm{mM}$ sodium phosphate, $\mathrm{pH} 6.5,100 \mu \mathrm{g} / \mathrm{ml}$ of sonicated and denatured salmon testes DNA, $2 \times$ Denhardt's solution, and $10 \%$ dextran sulfate at $42^{\circ} \mathrm{C}$ for $16-20 \mathrm{hr}$; and washing in $0.1 \times \mathrm{SSC}$ and $0.1 \%$ sodium dodecyl sulfate at room temperature and $50^{\circ} \mathrm{C}$ for $1 \mathrm{hr}$ each]. The DNA fragments described above were cloned into pGEM-3Z. To obtain antisense probes, the plasmids were linearized with $E c o$ RI and transcribed with the Gemini II system (Promega, Madison, WI) using SP6 RNA polymerase and ${ }^{35}$ S-uridine $5^{\prime}$ - $[\alpha$-thio $]$ triphosphate (DuPont-New England Nuclear, Boston, MA). Sense probes were prepared from IIindIII-linearized plasmid DNA using T7 RNA polymerase. The probes were diluted to $10^{7}$ $\mathrm{cpm} / \mathrm{ml}$ in $10 \mathrm{ml}$ aliquots of hybridization mixture that contained $50 \%$ formamide, $10 \mathrm{mM}$ Tris $\mathrm{HCl}$, pH 8 (GIBCO-Bethesda Research Labs, Gaithersburg, MD), $5 \mathrm{mg}$ tRNA (Boerhinger-Mannheim, Indianapolis, IN), $10 \mathrm{mM}$ dithiothreitol (DTT), $10 \%$ dextran sulfate, $0.3 \mathrm{M} \mathrm{NaCl}, 1$ mM EDTA, pH 8.0, and $1 \times$ Denhardt's solution (Sigma, St. Louis, $\mathrm{MO})$. Aliquots were stored at $-20^{\circ} \mathrm{C}$. Prior to use for in situ hybridization, mixtures were heated to $65^{\circ} \mathrm{C}$ for $10 \mathrm{~min}$ and centrifuged at $4000 \mathrm{rpm}$.

In situ hybridization. In situ hybridization was performed using methods similar to those described by Simmons et al. (1989). Briefly, five 6-8-week-old BalbC mice (Harlan Sprague-Dawley) were deeply anesthetized and perfused transcardially with saline followed by $4 \%$ paraformaldehyde solution at $\mathrm{pH} 6.5$ and then at 9.5 . Brains were postfixed overnight in the pH 9.5 fixative containing $20 \%$ sucrose. Serial $25 \mu \mathrm{m}$ coronal sections were cut on a sliding microtome and stored in a cryoprotectant solution (Simmons et al., 1989) containing 50\% neutral buffered formalin (Richard-Allan, Richland, MI) at $-20^{\circ} \mathrm{C}$ until they were mounted on gelatin-polylysine-subbed slides. Slides were dried in a vacuum desiccator overnight and immersed in $10 \%$ neutral buffered formalin for $2 \mathrm{hr}$ at $4^{\circ} \mathrm{C}$ immediately prior to hybridization, and then incubated in $0.001 \%$ proteinase K (Boehringer-Mannheim, Indianapolis, IN) for $30 \mathrm{~min}$, incubated in $0.025 \%$ acetic anhydride (Sigma, St. Louis MO) for $10 \mathrm{~min}$, and dehydrated in ascending concentrations of ethanol. One hundred and twenty microliters of hybridization mixture were applied to each slide, and a glass coverslip was applied (Clay Adams, Lincoln Park, NJ) and sealed with DPX (Gallard and Schleisinger, Calle Place, NY). Slides were incubated overnight at $56^{\circ} \mathrm{C}$. The following day, the slides were cooled to room temperature and the coverslips removed and washed four times in $4 \times \operatorname{SSC}$ (Sigma). Sections were incubated in a solution of $0.002 \%$ RNase A (Boehringer Mannheim), $0.5 \mathrm{M} \mathrm{NaCl}, 10 \mathrm{mM}$ Tris $\mathrm{HCl}, \mathrm{pH} 8$, and $1 \mathrm{mM}$ EDTA for 30 $\min$ at $37^{\circ} \mathrm{C}$ and rinsed in $2 \times, 1 \times, 0.5 \times$, and then $0.1 \times \mathrm{SSC}$ containing $0.25 \%$ DTT. Sections were incubated in $0.1 \times$ SSC with $0.25 \%$ DTT for $30 \mathrm{~min}$ at $60^{\circ} \mathrm{C}$, and dehydrated in $50 \%$ and $75 \%$ ethanol that contained $0.1 \times$ SSC and $0.25 \%$ DTT, followed by $95 \%$ and three changes of $100 \%$ ethanol. Slides were air dried and stored overnight in a vacuum desiccator. Sections were dipped in NTB2 photographic emulsion (Inter- national Biotechnologies Incorporated, New Haven, CT), dried, and stored with desiccant in foil-wrapped slide boxes at $4^{\circ} \mathrm{C}$ for $2-4$ weeks. Slides were developed with D-19 developer (Kodak, Rochester, NY), counterstained for $3 \mathrm{~min}$ in thionin, dehydrated in graded ethanols, cleared in xylene, and coverslipped with DPX (Gallard and Schlesinger).

Control studies. The specificity of in situ hybridization was determined by comparing the results of hybridization with antisense and sense probes to adjacent tissue sections. Northern blot analysis was also performed on mouse brain RNA using the inserts from the same DNA constructs used for in situ hybridization.

\section{Results}

In situ hybridization to sections of the adult mouse brain using SSTR 1- and SSIR2-specific probes showed distinctive patterns of expression of these genes with respect to both anatomical distribution and rclative level of expression. In contrast, hybridization with the sense-strand probe controls showed only sparse, diffusely scattered silver grains (Fig. 1). RNA blotting showed the presence of both SSTR1 and SSTR2 mRNAs in adult mouse brain (Fig. 2). The mouse SSTR1 and SSTR2 probes used for RNA blotting, which were the same as those used for the in situ hybridization studies described below, hybridized with distinct transcripts of 3.8 and 2.3 kilobases, respectively, and no cross-hybridization was observed using normal hybridization and washing conditions. The in situ hybridization results obtained with antisense cRNA probes were essentially identical in each of the five brains used in this study. SSTR 1 expression was observed throughout the mouse brain, particularly in forebrain regions and brainstem structures, whereas SSTR2 expression was limited to the forebrain. In most regions that we judged to contain specific hybridization, clusters of autoradiographic silver grains surrounded lightly thionin-stained nuclei. In some regions, especially regions with high densities of labeled cells, it was not possible to identify separate clusters. This was especially true in the piriform cortex, the stratum pyramidale of the hippocampus (Fig. $5 A, B$ ), and the granular layer of the dentate gyrus for both probes; in the periamygdaloid cortex, the bed nucleus of the anterior commissure, and the medial accessory olivary nucleus for SSTR1; and in the medial habenular nucleus for SSTR2 (Fig. 3C). In the absence of clustering, such hybridization was identified as specific by comparison to adjacent, unlabeled regions in the same section, and by the absence of such labeling in the sections hybridized with the sense probe. An overview of the pattern of hybridization is presented in Table 1. In the description that follows, the term density will be used to describe the number of grain clusters or compactness of nonaggregated grains in a nucleus or region; the intensity of hybridization will refer to the number of silver grains within an individual cluster.

\section{Anatomical distribution}

Telencephalon. Both receptor transcripts were expressed in the neocortex. SSTR 1 was primarily observed in the infragranular and, to a lesser extent, in the supragranular layers (Fig. $4 A$ ), and SSTR2 hybridization was observed only in the infragranular layer. Both forms were observed in cortical fields of the allocortex with distinct characteristics of laminar distribution and intensity (Fig. $4 A, B$ ). We have chosen representative regions of the mouse allocortex to present in Table 1. Light-to-medium levels of both forms were observed in the dorsal part of the hippocampus (Fig. 5A,B). The density and intensity of SSTR1 hybridization increased dramatically in a septotemporal and dorsal-to-ventral gradient, particularly in the stratum pyrami- 

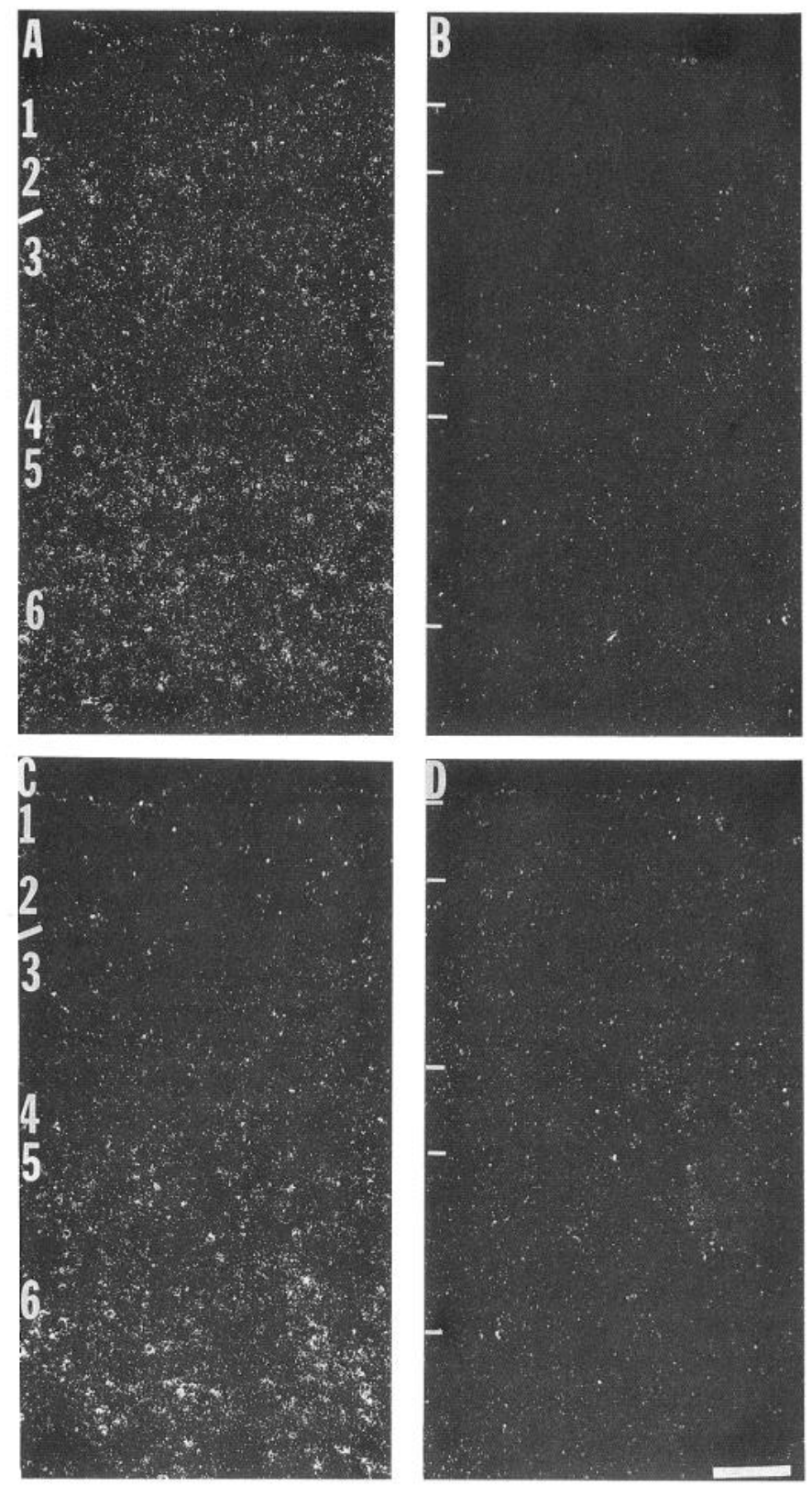

Figure 1. Dark-field photomicrographs of SSTR and SSTR2 expression in the neocortex of the mouse brain. $A$, SSTR1 expression in the second somatosensory cortex. Expression was densest in the infragranular layers 1 and 2. A moderate level of expression was observed in the supragranular layers 2 and 3. B, A dark-field photomicrograph of the adjacent mouse brain section hybridized with the sense-strand SSTR1 probe. $C$, SSTR2 expression in the second somatosensory cortex. Expression was primarily observed in the infragranular layers, although a few scattered clusters were observed in layers 2 and 3. D, A dark-field photomicrograph of the adjacent mouse brain section hybridized with the sense-strand SSTR2 probe. Scale bar, $200 \mu \mathrm{m}$.

dale of CA3, dentate granular layer, and subiculum (Fig. 4B). SSTR1 was observed throughout the nuclei of the amygdala (Fig. $4 A, B$ ), while SSTR2 expression was primarily observed in the lateral, basal magnocellular (Fig. $3 B$ ), and posterior cortical nuclei and in the amygdalohippocampal area. In the subcortical telencephalon, both forms were observed in the claustrum, endopiriform, and diagonal band nuclei. The claustrum contained the densest and most intense clusters of SSTR2 hybridization

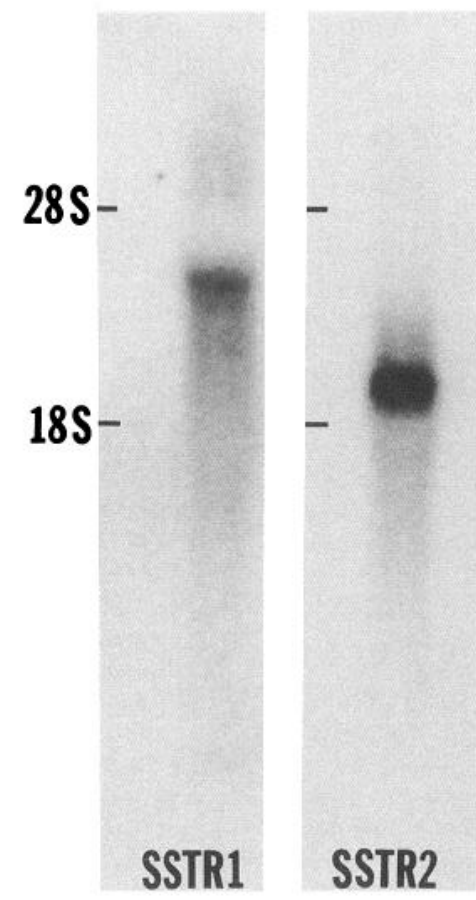

Figure 2. Northern blot analysis of SSTR1 and SSTR2 mRNA in the mouse brain. Twenty micrograms of mouse brain RNA were denatured with glyoxal, electrophoresed in a $1 \%$ agarose gel, blotted to a nylon membrane, and hybridized with nick-translated ${ }^{32} \mathrm{P}$-labeled inserts of the mouse SSTR1 or SSTR2 probes. Note the absence of cross-hybridization.

in the mouse brain (Fig. 3A). SSTR1 hybridization was also observed in the bed nucleus of the stria terminalis, ventrolateral part of the lateral septal nucleus, magnocellular preoptic nucleus (Fig. 6A), plexiform layer of the olfactory tubercle, ventral pallidum, globus pallidus, and substantia innominata. The density and intensity of clusters of SSTR1 hybridization in the substantia innominata increased in a rostral-to-caudal gradient. No hybridization with either SSTR1 or SSTR2 was observed in the caudate-putamen.

Diencephalon. There was little hybridization in the thalamus, although both SSTR forms were present in a limited distribution. A dense patch of high-intensity SSTR1 hybridization capped the dorsal part of the paraventricular nucleus of the thalamus, while the body of this nucleus was devoid of clusters. Sparse levels of light-intensity clusters were observed in the ventromedial part of the reticular nucleus of the thalamus, adjacent to the zona incerta. SSTR1 was also observed in the internal and dorsal, "relatively cell-free" zones of the ventral lateral geniculate nucleus (Swanson et al., 1974) and in the lateral habenular, posterior intralaminar, posterior limitans, and suprageniculate nuclei (LeDoux et al., 1985) and the zona incerta. The densest SSTR2 hybridization was observed in the medial habenular nucleus (Fig. 3C). Observation of this nucleus with high-power, bright-field magnification revealed a few very highintensity clusters within the very dense patch of apparently nonaggregated grains, suggesting that the pattern resulted from dense packing of moderately to intensely labeled clusters over individual cells.

In the hypothalamus, both SSTR forms were observed in the medial parvicellular subnucleus of the paraventricular nucleus and in the arcuate and posterior periventricular nuclei (Fig. 

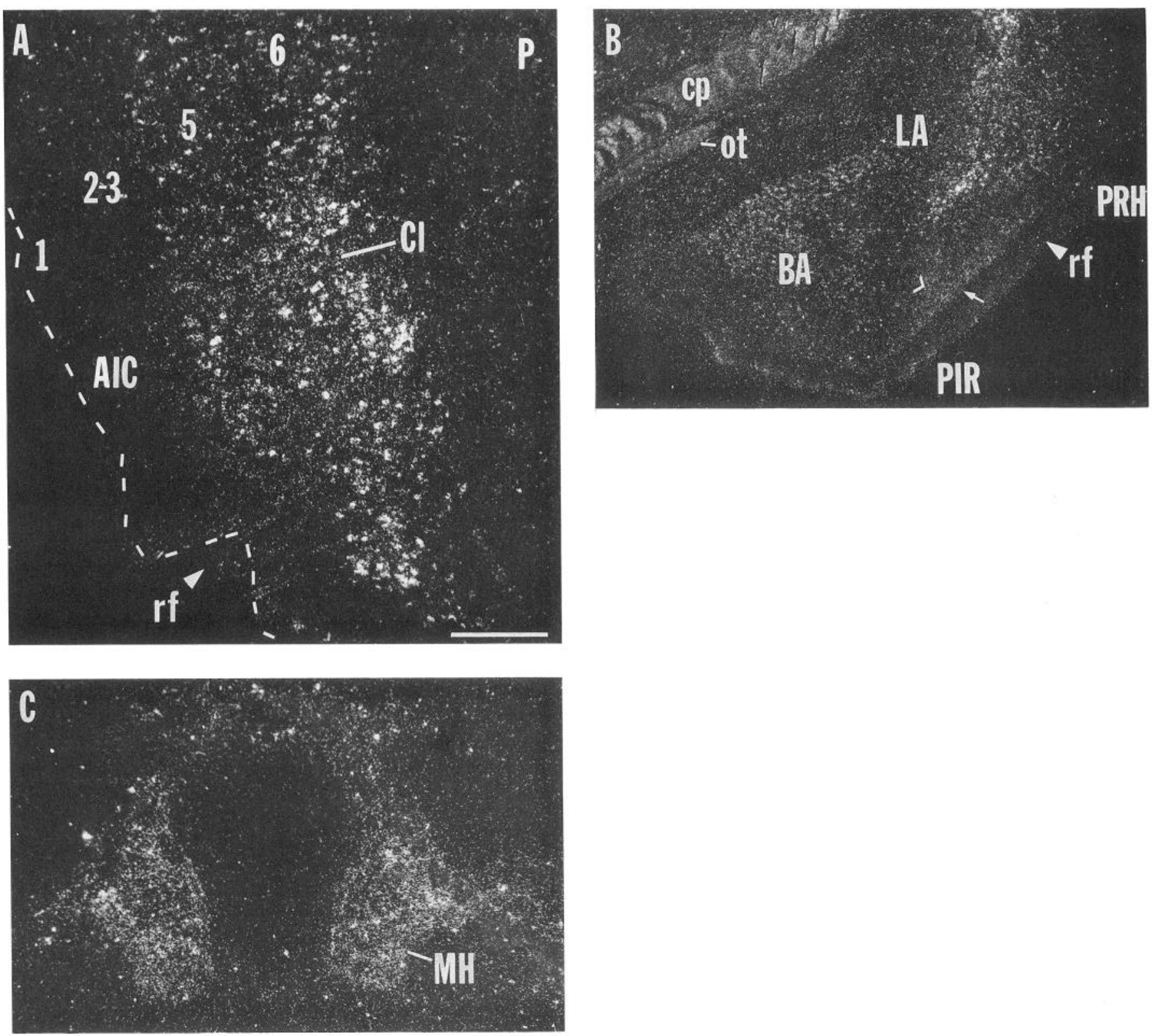

Figure 3. In situ hybridization showing expression of SSTR 2 in the forebrain. A, Dark-field photomicrograph demonstrating dense labeling in the claustrum $(C l)$ and endopiriform nucleus. Labeling in the agranular insular cortex $(A I C$; above the rhinal fissure, $r f)$ was restricted to layers 5 and $6 . B$, In the amygdala, hybridization was primarily observed in the lateral $(L A)$ and basal $(B A)$ magnocellular nuclei. Labeling in the adjacent perirhinal cortex $(P R H)$ was limited to the deeper layers, while in the piriform cortex $(P I R)$, clusters were primarily observed over layer 2 (arrow) and to a lesser extent in layer 3 (arrowhead). $C$, In the epithalamus, dense SSTR2 hybridization was observed in the medial habenular nucleus $(M H) .1-6$, layers of the insular cortex; $c p$, cerebral peduncle; ot, optic tract; $P$, putamen. Scale bar: $250 \mu \mathrm{m}$ for $A ; 950 \mu \mathrm{m}$ for $B ; 35 \mu \mathrm{m}$ for $C$.

$4 A, B)$. In the arcuate nucleus, the densest and most intense clusters of hybridization of both SSTR1 and SSTR2 were seen in the dorsal and ventrolateral part of the nucleus, while moderate levels of medium-intensity clusters were observed in the ventromedial part. Dense SSTR 1 hybridization was also present in the ventral part of the suprachiasmatic nucleus, and more moderate hybridization was observed throughout the preoptic, anterior, tuberal, and posterior hypothalamus (Fig. $4 A, B$ ). In the tuberal part of the lateral hypothalamic area, a group of clusters extended with a gradient of decreasing density from the ventrolateral edge of the fornix to the ventromedial edge of the optic tract (Fig. 4A). SSTR2 hybridization was also observed in the internal lamina of the median eminence and the retrochiasmatic and lateral hypothalamic areas. In the posterior part of the lateral hypothalamic area, clusters of silver grains extended from the ventrolateral edge of the fornix to the ventromedial edge of the internal capsule.

Midbrain and pretectal area. SSTR1 hybridization was observed in several nuclei in the midbrain including the superior and inferior colliculi, periaqueductal gray matter, substantia nigra pars reticulata, the nucleus of the optic tract, and the anterior pretectal, anteromedian, Edinger-Westphal, and dorsal and median raphe nuclei (Fig. 7A). No SSTR2 expression was observed in these levels of the mouse brain. The density of SSTR 1 clusters 
Table 1. Pattern of expression of SSTR1 and SSTR2 mRNAs in the brain of the adult mouse

Region

Telencephalon

Isocortex

I

II-III

IV

V-VI

$++$

$+$

$++$

$+++$

Allocortex (cortical fields)

Piriform cortex

I

II

III

$\frac{++}{\overline{++}}$

Anterior cingulate cortcx

I

II-IV

$\mathrm{V}$

VI

Dysgranular insular cortex

II-III

IV

$\mathrm{V}$

VI

Agranular insular cortex ${ }^{2}$

I

II-III

$\mathrm{V}$

VI

Granular retrosplenial cortex ${ }^{3}$

I

II-III

IV

$\mathrm{V}$

VI

Agranular retrosplenial cortex ${ }^{3}$

II-III

$\mathrm{V}$

VI

$\begin{array}{ll}- & - \\ \frac{++}{++} & ++\end{array}$

$-$

$++$

$+++$

$++$

$++$

$-$

$++$

$+$

$++$

$++$

$\frac{t+}{t}$

ippocampus

Dorsal part

Subiculum

CA1

Stratum pyramidale

Suprapyramidal

Infrapyramidal

CA3

Stratum pyramidale

Suprapyramidal

Infrapyramidal

Dentate gyrus

Granular layer

Molecular layer

Hilus

Ventral part

Subiculum

CA1

Stratum pyramidale

Suprapyramidal

$-$

$++$

$++$

$+$

$-$

$+$

$++$

$+$

$++$

$++$

$++$

$++$

$+++$

$++$

$-$

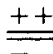

$++$

$++$

$++$

(

$++$

$-$

$-$

$t+$

$++$

$++$

$++$

Infrapyramidal

$+$

$\stackrel{++}{\overline{+}}$

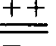

$+$

$\frac{+}{+}$
+

$\stackrel{+}{=}$

$+$

$\frac{t+}{\frac{t}{\bar{t}}}$

$\pm$

$+++\quad++$

$\begin{array}{ll}++ & ++ \\ ++ & +\end{array}$ 
Table 1. Continued

Region

CA3

Stratum pyramidale

Suprapyramidal

Infrapyramidal

Dentate gyrus, granular layer

Amygdala ${ }^{4}$

$N$. of the lateral olfactory tract, layers $2-3$

Medial $\mathbf{n}$.

Superficial layer

Deep part

Anterior cortical $n$.

Layer 1

Layer 2

Layer 3

Periamygdaloid cortex

Layer 1

Layer 2

Layer 3

Lateral $\mathbf{n}$.

Basal n.

Magnocellular division

Parvocellular division

Central $\mathrm{n}$.

Medial part

Latcral part

Accessory basal $\mathrm{n}$.

Posterior cortical $\mathrm{n}$.

Amygdalohippocampal area

Subcortical telencephalon

Claustrum

Endopiriform $\mathrm{n}$.

Olfactory tubercle, Plexiform layer

Bed $\mathbf{n}$. of the stria terminalis

Medial zone

Central zone

Lateral zone

Preoptic portion

Bed $\mathrm{n}$. of the anterior commissure

Lateral septal $n,{ }^{5}$ Ventrolateral part

Nucleus of the diagonal band

Vertical part

Horizontal part

Magnocellular preoptic $n .^{6}$

Substantia innominata

Striatum

Globus pallidus

Ventral pallidum

Diencephalon

Thalamus

Medial habenular $\mathbf{n}$.

Lateral habenular $\mathrm{n}$.

Paraventricular n. (rostral, dorsal part)

Reticular $\mathbf{n}$.

Ventral lateral geniculate $n .^{7}$

Posterior intralaminar $n .^{8}$

Suprageniculate $n .^{8}$

Posterior limitans $n .^{8}$

Hypothalamus 9

Vascular organ of the lamina terminalis

\section{SSTR1 mRNA SSTR2 mRNA}

$\begin{aligned} & +++ \\ & + \\ & ++ \\ & ++++ \\ & ++ \\ & +++ \\ & ++ \\ & + \\ & +++ \\ & ++\end{aligned}$

$-$

$\stackrel{++}{\underline{++}}$

$+++\quad+++$

$++\quad++$

$+++\quad++$

$+$

$++$

$++\quad-$

$+++\quad++$

$+++\quad++$

$+++\quad+++$

$++\quad+++$

$+\quad-$

$+$

$++$

$+$

$+\quad-$

$\stackrel{+++}{+}$

$++\quad+$

$++$

$+++$

$+++$

$+$

$+\quad-$

$\begin{array}{ll}- & \stackrel{++++}{=} \\ + & - \\ +++ & - \\ + & - \\ ++ & - \\ ++ & - \\ + & - \\ 1 & -\end{array}$




\section{Table 1. Continued}

Region

Median preoptic $n$.

Anteroventral periventricular $n .{ }^{10}$

Periventricular preoptic $n$.

Medial preoptic $n$.

Median preoptic area

Lateral preoptic area

Anterior hypothalamic area

Periventricular $\mathrm{n}$.

Suprachiasmatic n., ventral portion

Paraventricular $\mathrm{n}$.

Anterior parvicellular subn.

Medial parvicellular subn.

Dorsal subn.

Lateral parvicellular subn.

Posterior magnocellular subn.

Retrochiasmatic arca

Arcuate and posterior periventricular $n$.

Median eminence, internal lamina

Dorsomedial $\mathbf{n}$.

Ventromedial $\mathbf{n} .^{11}$

Dorsomedial part

Ventrolateral part

Perifornical area

Lateral hypothalamic area

Supramammillary $n$.

Posterior hypothalamic area

Pretectum $^{12}$ and midbrain

$\mathrm{N}$. of the optic tract

Anterior pretectal $\mathrm{n}$.

Ventral tegmental area

Substantia nigra, pars reticulata

Peripcduncular $\mathbf{n}$.

Superior colliculus

Superficial

Intermediate

Deep

Inferior colliculus ${ }^{13}$

Internal division

External division

Interpeduncular $\mathrm{n} .^{14}$

Rostral dorsal, caudal dorsal and caudal lateral subn.

Anteromedian $\mathrm{n}$.

Edinger-Westphal $\mathbf{n}$.

Periaqueductal gray matter

Dorsolateral

Ventrolateral

Medial

Raphe $n .{ }^{15}$

Dorsal $\mathrm{n}$.

Median $\mathbf{n}$.

Cuneiform $\mathbf{n}$.

Pedunculopontine tegmental $\mathbf{n}$.

Central tegmental $n$.

Pons

Parabrachial n. ${ }^{16}$

Central lateral subn.

Dorsal lateral subn.

External lateral subn.
SSTR1 mRNA SSTR2 mRNA

$++\quad-$

$++$

$++$

$+++$

$++$

$++$

$++$

$+$

$+++$

$+$

$++$

$+$

$+$

$+$

$+$

$+++$ $-$

$-$

-

-

-

$-$

$-$

$-$

$-$

$-$

$+$

$++$

$+$

$+$

$++$

$++$

$++$

$+$

$+$

$+++$

$++$

$+$

$+$

$+++$

$++$

$+$

$+++$

$+$

$++$

$++$

$+$

$++$

$+$

$+$

$++$

$++$

$++$

$++$

$+$

$+$

$+$ $\underline{\underline{+}}$

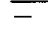

$-$

$++$

$++$

$+$

- 


\begin{tabular}{|c|c|c|}
\hline Region & SSTR 1 mRNA & SSTR 2 mRNA \\
\hline Internal lateral subn. & ++ & - \\
\hline Superior lateral subn. & ++ & - \\
\hline Ventral lateral subn. & ++ & - \\
\hline Medial $\mathbf{n}$. & +++ & - \\
\hline External medial subn. & +++ & - \\
\hline Kölliker-Fuse n. & ++ & - \\
\hline Locus coeruleus & +++ & - \\
\hline Mesencephalic $n$. of $V$ & ++ & - \\
\hline Principle $n$. of $V$ & $+t$ & - \\
\hline \multicolumn{3}{|l|}{ Medulla } \\
\hline \multicolumn{3}{|l|}{ N. of the solitary tract ${ }^{17}$} \\
\hline Rostral part & $+t$ & - \\
\hline Medial subn. & +++ & - \\
\hline Dorsomedial subn. & ++ & - \\
\hline Parvicellular subn. & +++ & - \\
\hline Ventrolateral subn. & $+t$ & - \\
\hline Commissural subn. & ++ & - \\
\hline \multicolumn{3}{|l|}{ Area postrema } \\
\hline Lateral part & ++++ & - \\
\hline Core & + & - \\
\hline Subpostrema & ++ & - \\
\hline Dorsal motor $\mathrm{n}$. of $\mathrm{X}$ & + & - \\
\hline N. ambiguus & + & - \\
\hline Hypoglossal $\mathrm{n}$. & + & - \\
\hline Reticular formation, parvicellular part ${ }^{17}$ & ++ & - \\
\hline \multicolumn{3}{|l|}{ Spinal $n$. of $V^{18}$} \\
\hline Subn. zonalis & +++ & - \\
\hline Subn. gelatinosa & + & - \\
\hline Gigantocellular field, pars alpha & + & - \\
\hline Medial accessory olive & ++ & - \\
\hline \multicolumn{3}{|c|}{$\begin{array}{l}\text { Relative distribution of SSTR1 and SSTR } 2 \text { in the mouse brain is expressed in the following density range for clusters } \\
-, \text { not observed; }+, \text { rare clusters; }++, \text { moderate numbers of lightly labclcd clustcrs; }+++, \text { moderatc numbers o } \\
\text { intensely labeled clusters; }++++ \text {, frequent, moderately or intensely labeled clusters. Double underline }(\text { e.g., }++) \text { denote }\end{array}$} \\
\hline \multicolumn{3}{|c|}{$\begin{array}{l}\text { the relative density of nonaggregated grains. I-IV, cortical laminae; } n \text {., N., nucleus; } n \text {. of V, nucleus of the trigemina } \\
\text { nerve; n. of X, nucleus of the vagal nerve. Nomenclature derived from specific literature citations is noted: } 1 \text {. Cechetto } \\
\text { and Saper, 1987; 2. Saper, 1982; 3. Zilles, 1985; 4. Price et al., 1987; 5. Swanson and Cowan, 1979; 6. Saper, 1984 } \\
\text { 7. Swanson et al., 1974; 8. LeDoux et al., 1985; 9. Swanson, 1987; 10. Saper et al., 1983; 11. Saper et al., 1976 } \\
\text { 12. Scalia, 1972; 13. Berman, 1968; 14. Hemmendinger and Moore, 1984; 15. Taber et al., 1960; 16. Fulwiler and } \\
\text { Saper, 1984; 17. Herbert et al., 1990; 18. Olszewski, 1960. }\end{array}$} \\
\hline
\end{tabular}

in the superior colliculus increased in a rostral-to-caudal gradient and posteriorly covered the intermediate and deep layers with a continuous layer of clusters.

Pons. SSTR1 hybridization was also observed in several nuclei of the pons, particularly the locus coeruleus, mesencephalic and principle sensory nuclei of the trigeminal nerve, and the parabrachial nucleus, while no pontine SSTR2 expression was observed. SSTR 1 clusters were especially prominent in the ventral part of the locus coeruleus.

Medulla. SSTR1 hybridization was also observed in several regions of the medulla, and was especially dense in the dorsal vagal complex (Fig. $7 B$ ). In the spinal trigeminal nucleus, dense clusters of silver grains were grouped inside the medial (deep) border of the gelatinous subnucleus, adjacent to the magnocellular subnucleus (Olszewski, 1960). SSTR2 hybridization was not observed in this level of the brain.

Cerebellum. Neither SSTR I or SSTR2 hybridization was observed in this part of the adult mouse brain.

\section{Discussion}

We have used cRN $\Lambda$ probes to investigate the distribution of two SSTR forms, termed SSTR1 and SSTR2, in the mouse brain. SSTR1 expression was observed throughout all levels of the brain, particularly in the cortex, hippocampus, amygdala, and several brainstem structures, while SSTR2 was only observed in forebrain structures (Fig. 8). Sense transcript hybridization resulted in only background levels of silver grains. The data suggest that SSTR1 and SSTR2 have distinct patterns of expression both with regard to location and level of expression in the adult mouse brain.

\section{Cellular localization}

In this study, we describe the characteristic regional distribution of SSTR 1 and SSTR 2 mRNAs and propose that these patterns represent neuronal hybridization. The hybridization was restricted to specific nuclei and areas, and in most areas the ag- 

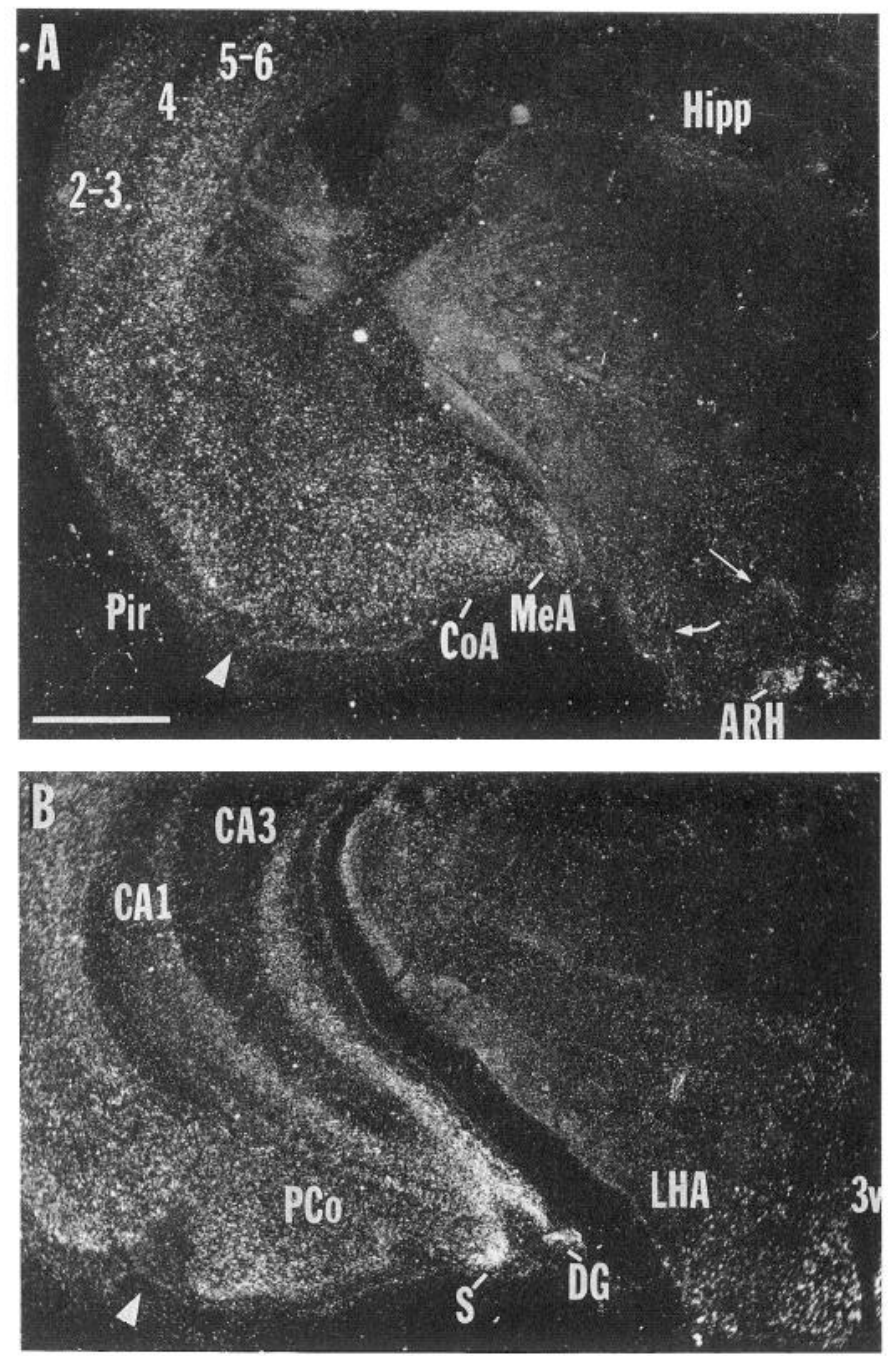

Figure 4. Dark-field photomicrographs of SSTR1 hybridization. A, Anterior tuberal hypothalamus, amygdala, and adjacent cortex. At this level, hypothalamic labeling was primarily observed in the arcuate nucleus $(A R H)$, extending in an arc (curved arrow) from the fornix to the ventromedial edge of the optic tract in the lateral hypothalamic area, and in a crescent-shaped cap (straight arrow) corresponding to the dorsomedial part of the ventromedial nucleus of the hypothalamus. Hybridization was observed throughout the amygdala, particularly in the anterior cortical $(C O A)$, medial $(M e A)$, basal magnocellular, lateral, and central nuclei, as well as in the periamygdaloid cortex. Pronounced labeling was observed in the supra- and infragranular layers of the cerebral cortex. $B$, At the posterior tuberal hypothalamic level, expression was observed in the arcuate nucleus and lateral hypothalamic area $(L H A)$. In the telencephalon, very dense labeling was observed in the posterior cortical nucleus of the amygdala $(P C o)$, subiculum $(S)$, dentate granule cell layer $(D G)$, CA3 cell field of the ventral hippocampal formation (CA3), and entorhinal cortex. The arrowhead indicates the rhinal fissure. $1-6$, cortical laminae; $3 v$, third ventricle; Hipp, dorsal part of the hippocampus. Scale bar, $800 \mu \mathrm{m}$.

gregated silver grains constituted the clusters that surrounded thionin-stained neuronal nuclei. We saw only diffuse hybridization over cell groups with a high packing density of labeled cells, and even in these cases, some clusters of silver grains could still be identified over cell bodies. Neither receptor form was observed in regions such as the cerebellum, caudate-putamen (Fig. 3A), or ventrobasal nuclei of the thalamus (Fig. 4B), nor was labeling observed over fiber tracts. These results suggest that the hybridization was both specific and neuronal, as SSTR
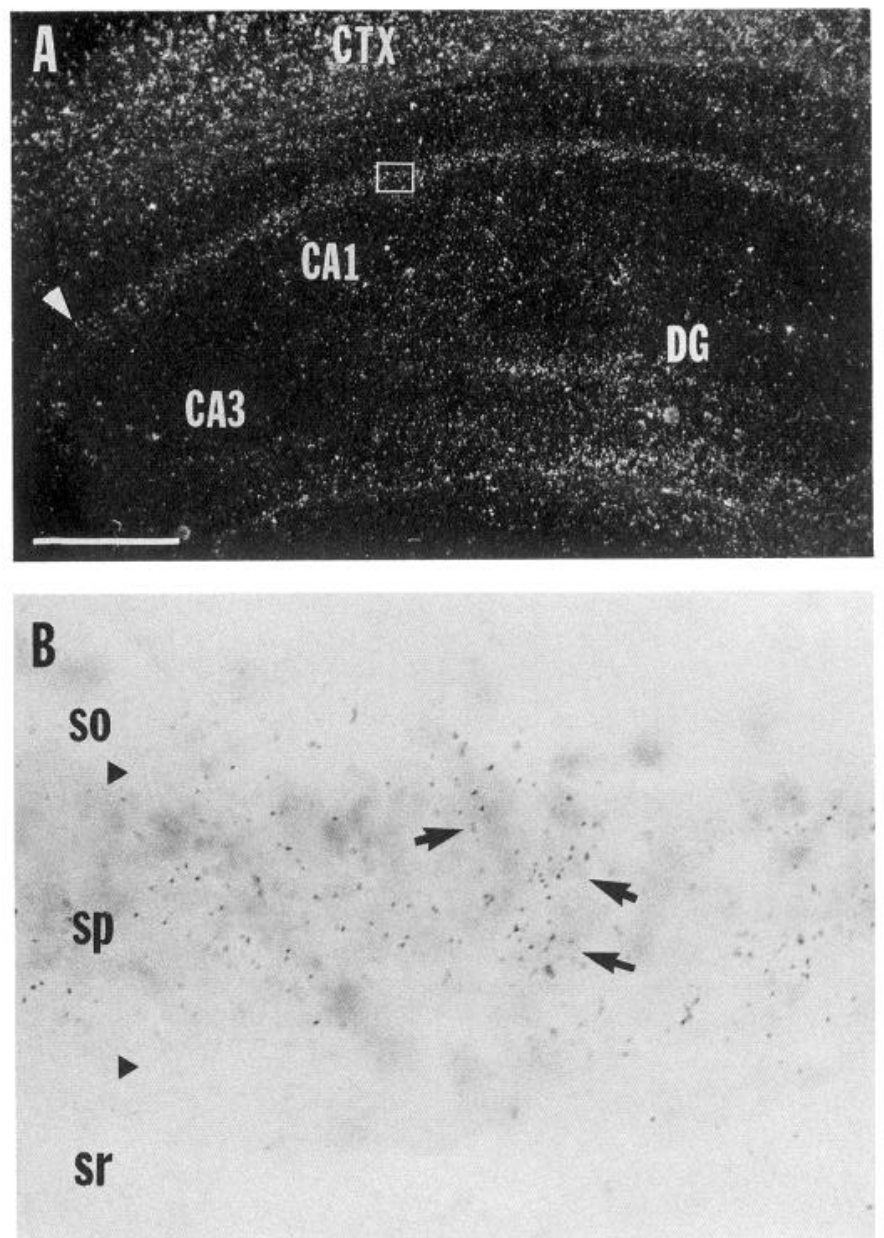

Figure 5. In situ hybridization showing expression of SSTR1 in the rostral dorsal part of the hippocampus. $A$, A dark-field photomicrograph illustrating the density of diffuse hybridization over the pyramidal ( $s p$; see labels in $B$ ) and granule cell layers. The arrowhead delineates the border of between the CA1 and CA2 cell fields of the hippocampus. Sparse clusters of silver grains were observed in the stratum oriens $(s o)$ and infrapyramidal cell layers, particularly in the stratum radiatum $(s r)$ of the CA fields. Moderate numbers of grain clusters were observed in the hilus of the dentate gyrus $(D G)$ at this level. $B$ High-power photomicrograph of the boxed area in the CAl field in $A$ depicting the restricted distribution of grains over the pyramidal cell body layer. Note the tendency of silver grains to cluster (arrows) over the densely packed cell layer. $C T X$, cortex. Scale bar: $400 \mu \mathrm{m}$ for $A ; 40 \mu \mathrm{m}$ for $B$.

transcripts in astrocytes, microglia, or oligodendroglia would be expected to give rise to a more widespread pattern.

\section{Anatomical considerations: comparison to receptor binding studies}

The patterns of SSTR 1 and SSTR 2 hybridization in the mouse brain were similar to portions of the previously described anatomical distributions of binding sites of SST-14, SST-28, and their analogs in the mammalian brain. Several studies have mapped the distribution of SST-14 binding sites in the rat brain (Leroux et al., 1985; Whitford et al., 1987). Scatchard analysis of the binding of this ligand with rat brain membranes suggested the presence of two high-affinity binding sites (Weightman et al., 1985). The distribution of the regions with the densest binding in these studies (cf. Fig. $1 C$ of Whitford et al., 1987) is remarkably similar to the pattern of SSTR 2 hybridization, par- 

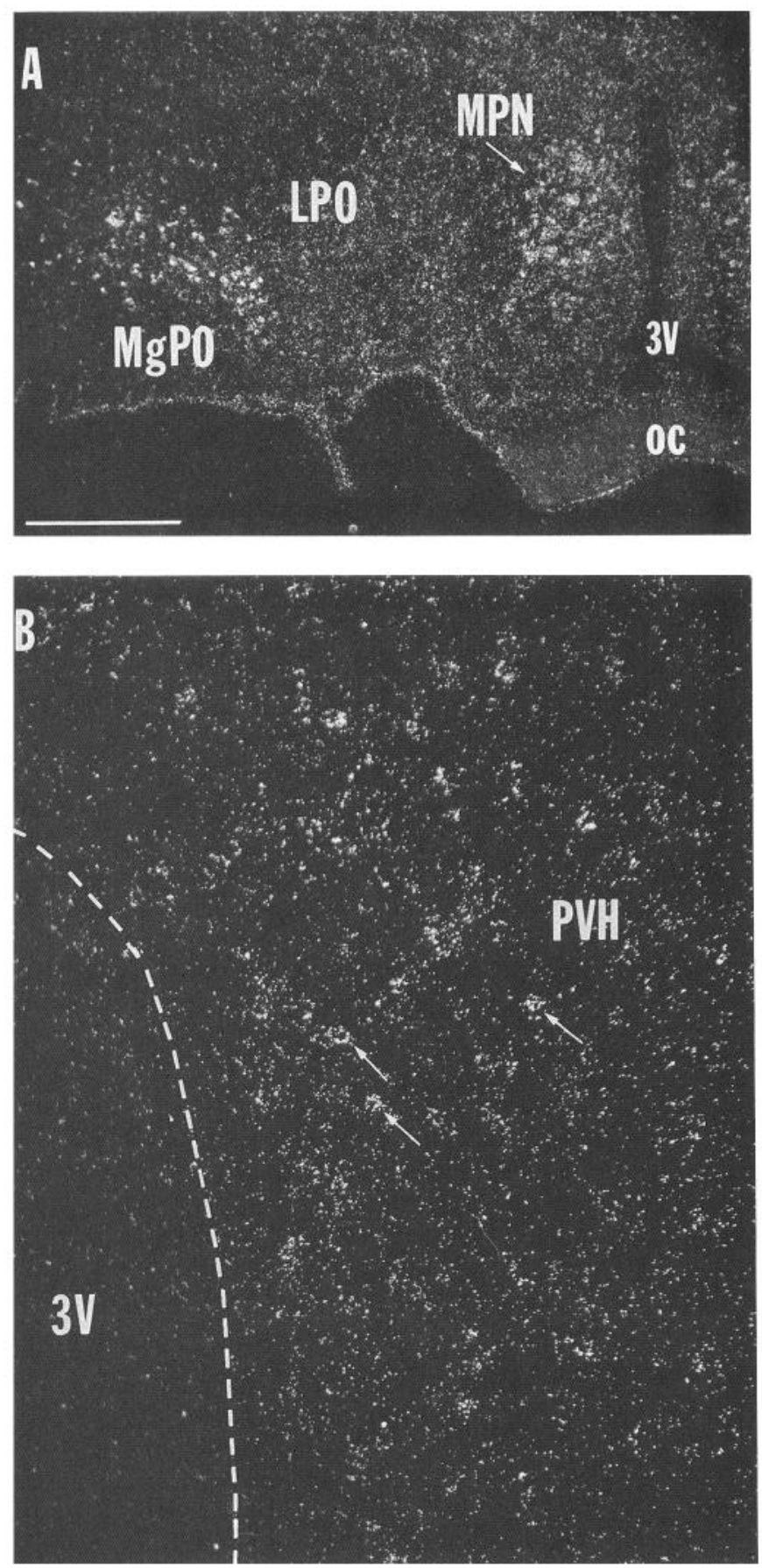

Figure 6. Dark-field photomicrograph of in situ hybridization showing expression of SSTR 1 at the level of the basal forebrain. A, Preoptic level of the diencephalon. Dense hybridization was observed in the medial $(M P N)$ and magnocellular $(M g P O)$ preoptic nuclei. $B$, In the paraventricular nucleus of the hypothalamus $(P V H)$, clusters of silver grains (arrows) were observed in the parvicellular divisions. $3 \mathrm{~V}$, third ventricle; $L P O$, lateral preoptic area; $o c$, optic chiasm. Scale bar: $300 \mu \mathrm{m}$ for $A$; $120 \mu \mathrm{m}$ for $B$.

ticularly in the cortex, claustrum, and amygdala (Fig. $3 A, B$ ). Several SST-14 binding regions such as the lateral septum, nucleus of the lateral olfactory tract, inferior colliculus, and locus coeruleus exhibited only SSTR1 hybridization.

SST-28 (Leroux et al., 1985) and the analog LTT-S28 (Uhl et al., 1985; Patel et al., 1986; Leroux et al., 1991) have been used to investigate the distribution of putative SST-28 binding
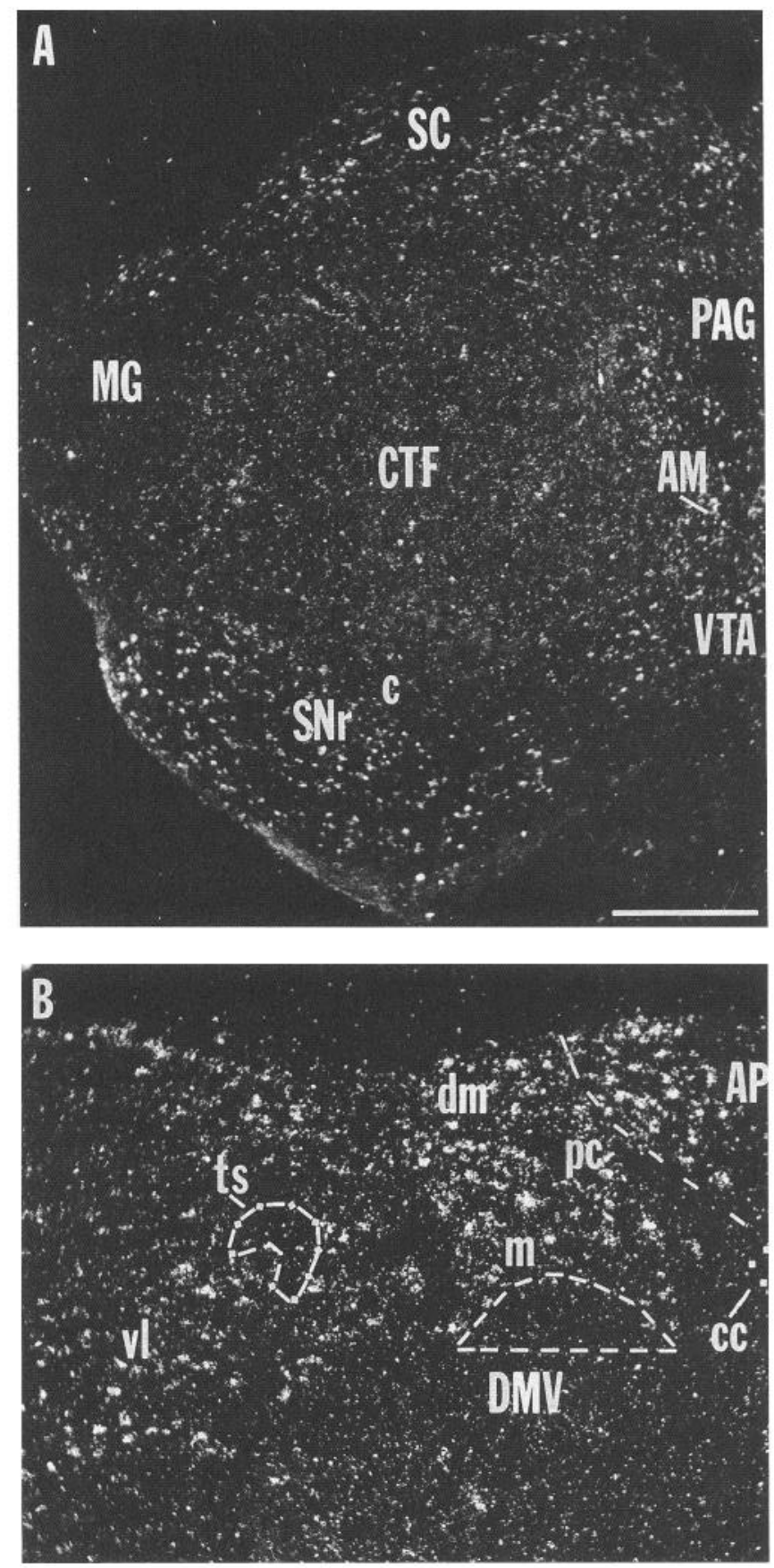

Figure 7. Dark-field photomicrographs of SSTR1 mRNA expression in the brainstem. $A$, In the midbrain, heavy clusters were observed in the substantia nigra pars reticulata $(S N r)$. SSTR1 hybridization extended through the ventral tegmental area $(V T A)$, into the periaqueductal gray matter $(P A G)$, and over the Edinger-Westphal nucleus. Labeling also circumscribed the medial geniculate body $(M G)$ and extended into the pretectum and tectum. In anterior tectum, hybridization was primarily observed in the intermediate layer of the superior colliculus $(S C) . B$, Dense SSTR 1 expression was also observed in the dorsal vagal complex. Dense levels of very high-intensity clusters were observed in the area postrema $(A P)$ and in the medial $(m)$ and parvicellular $(p c)$ subnuclei of the nucleus of the solitary tract. Clusters were also observed in the dorsomedial $(\mathrm{dm})$ and ventrolateral $(\mathrm{vl})$ solitary subnuclei. Few clusters were observed over the dorsal motor vagal nucleus ( $D M V$ ). $A M$, anteromedian nucleus; $c$, commissural subnucleus of the solitary tract; $c c$, central canal; $C T F$, central tegmental field; $t s$, solitary tract. Scale bar: $800 \mu \mathrm{m}$ for $A ; 400 \mu \mathrm{m}$ for $B$. 


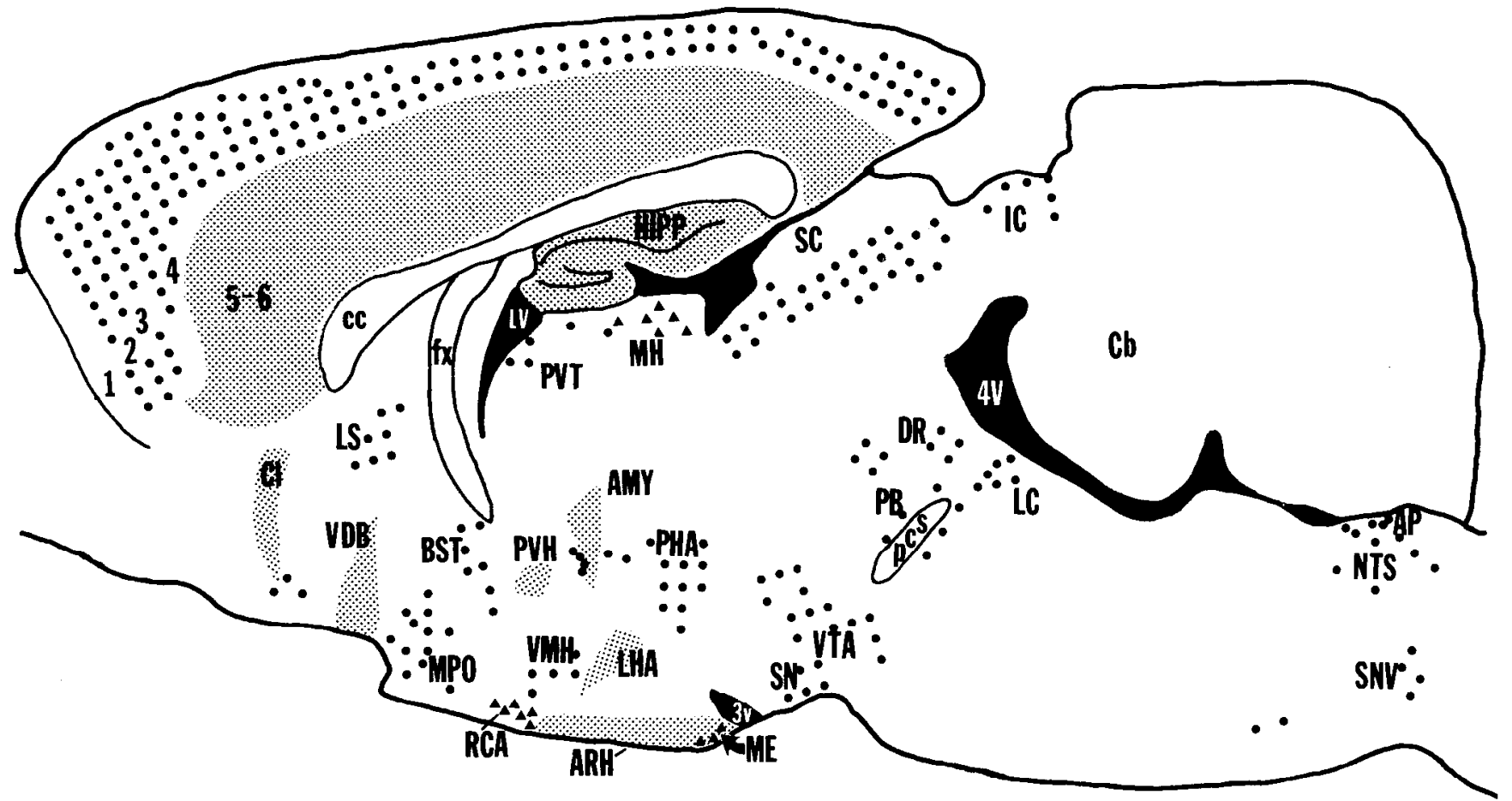

Figure 8. Schematic diagram of a sagittal section of the mouse brain illustrating the distribution of SSTR1 and SSTR2. Shading, Regions that expressed both SSTR1 and SSTR2; circles, SSTR1 only; triangles, SSTR2 only. $1-6$, cortical laminae; $3 v$, third ventricle; $4 V$, fourth ventricle; $A M Y$, amygdala; $A P$, area postrema; $A R H$, arcuate nucleus of the hypothalamus; $B S T$, bed nucleus of the stria terminalis; $C b$, cerebellum; $c c$, corpus callosum; $C l$, claustrum (and endopiriform nucleus); $D R$, dorsal raphe nucleus; $f x$, fornix; $H I P P$, hippocampus; $I C$, inferior colliculus; $L C$, locus coeruleus; $L H A$, lateral hypothalamic area; $L S$, lateral septal nucleus; $L V$, lateral ventricle; $M E$, median eminence; $M H$, medial habenular nucleus; $M P O$, medial preoptic nucleus (and the anteroventral region around the third ventricle); $N T S$, nucleus of the solitary tract; $P B$, parabrachial nucleus; $P H A$, posterior hypothalamic area; $P V H$, paraventricular nucleus of the hypothalamus; $P V T$, paraventricular nucleus of the thalamus; $R C A$, retrochiasmatic area; $S C$, superior colliculus; $S c p$, superior cerebellar peduncle; $S N$, substantia nigra, pars reticulata; $S N V$, spinal nucleus of the trigeminal nerve; $V D B$, vertical limb of the nucleus of the diagonal band; $V M H$, ventromedial nucleus of the hypothalamus; $V T A$, ventral tegmental area.

sites in the rat brain. Both ligands bind to numerous structures in the rat brain, most of which are consistent with the pattern of expression of SSTR 1 mRNA. However, the medial habenular nucleus (Leroux et al., 1985; Uhl et al., 1985) and the median eminence (Reubi et al., 1987), where only SSTR2 hybridization was observed, bound moderate-to-high amounts of SST-28 in these studies. Furthermore, SSTR 2 hybridization was observed in many of the regions with the highest ligand binding, such as the infragranular layers of the cortex (Fig. $3 A$ ), basal and lateral nuclei of the amygdala (Fig. $3 B$ ), and the arcuate and paraventricular nuclei of the hypothalamus (Uhl et al., 1985). These results suggest that these ligands may be less selective in labeling specific SSTR forms, or that they may recognize additional subtypes.

Rens-Domiano et al. (1992) recently showed selective binding of the SST analog CGP-23996 to Chinese hamster ovary cells expressing SSTR1 and of another analog, MK-678, to cells expressing SSTR2. In binding studies (Epelbaum et al., 1985; Martin et al., 1991), MK-678 labeled the claustrum more heavily than CGP-23996, which is consistent with the relatively denser level of hybridization of SSTR2 than SSTR1 observed in our study. The relative binding of these ligands in the basal and lateral nuclei of the amygdala (Fig. $4 A$ ) and the CAl field of the hippocampus (Fig. 5A,B) were also congruous with our findings. In addition, higher levels of MK-678 binding were observed in the medial habenular nucleus (Martin et al., 1991), which showed dense SSTR2 hybridization (Fig. 3C). Numerous regions where
MK-678 binding was observed did not display SSTR2 hybridization, particularly the medial and cortical nuclei of the amygdala, paraventricular nucleus of the thalamus, superior colliculus, periaqueductal gray matter, and the interpeduncular and peripeduncular nuclei, yet wc obscrved moderate-to-dense levels of SSTR 1 hybridization in these areas (Figs. $4 A, B ; 6 A$ ). Martin et al. (1991) noted a lower level of CGP-23996 binding between the supra- and infragranular layers of the prefrontal cortex and labeling in the substantia nigra restricted to the pars reticulata. Both of these observations were strikingly similar to the pattern of hybridization we observed with the SSTR I probe (Figs. 4A, $B, 6 A$ ). Epelbaum et al. (1985) observed CGP-23996 binding in the lateral habenular nucleus and anterior pretectal, trigeminal, and parabrachial nuclei; our studies showed that each of these regions expressed SSTR1 mRNA (Table 1). By contrast, low levels of CGP-23996 binding in the hypothalamus and elevated MK-678 binding in the striatum and substantia nigra pars compacta were inconsistent with the specificity of these ligands for SSTR1 and SSIR2.

Certain discrepancies exist between the pattern of SSTR 1 and SSTR2 expression in the adult mousc brain and the distribution of binding sites for SST and its analogs in the rat brain. While this may be a species difference, in part it may reflect the fact that protein levels may be regulated by posttranscriptional events beyond cellular mRNA levels. In addition, there may be other SSTR isoforms expressed in brain in addition to SSTR 1 and SSTR2. Finally, considerable ultrastructural (Alonso et al., 1985; 
Obata-Tsuto, 1987) and pharmacological (Ipp ct al., 1979; Pcterfreund and Vale, 1984) data support the existence of SST autoreceptors. In this instance, the presynaptic receptor located on the axon terminal and its mRNA (located in the cell body) would not have the same regional distribution. Despite these caveats, the distribution of SSTR1 and SSTR2 hybridization displays some striking similarities and interesting differences with respect to ligand binding distributions.

\section{Heterogeneity of SSTRS}

Functional considerations. SST has been implicated in the control of neuroendocrine (Brazeau et al., 1973), autonomic (Brown, 1988), and cognitive function (Beal et al., 1986). We observed extensive hybridization in regions of the CNS thought to regulate these functions, as well as in nuclei involved in sensory afferent processing. In most of the latter regions, SSTR 1 and SSTR2 were observed in divisions or subnuclei that conncctional and physiological data suggest are involved in the processing of polymodal rather than primary sensory afferent information. These areas are discussed in conjunction with those traditionally thought to be involved in cognitive function.

Neuroendocrine regulation. SST was first isolated from the hypothalamus because of its ability to inhibit pituitary secretion of GH. SST is also active in the hypothalamo-hypophysial axis in the regulation of thyrotropin- and luteinizing hormone-releasing hormone (-RH) secretion (Lumpkin et al., 1981), as well as in the regulation of the magnocellular secretory system (Brown, 1988; Rettig et al., 1989), particularly vasopressin secretion.

The relationship of central SST systems to hypophysial GH secretions is currently a topic of intense interest and increasing complexity. Immunohistochemical and pharmacological data provide evidence for at least two functionally distinct populations of SST-immunoreactive neurons in the periventricular and mediobasal hypothalamus. Double-labeling experiments combining subpial injections of HRP into the median eminence with SST immunohistochemistry suggest that neurons in the anterior periventricular hypothalamus and parvicellular portions of the paraventricular nucleus of the hypothalamus give rise to the neurosecretory projection to the neurohemal zone of the median eminence (Merchenthaler et al., 1989). Ultrastructural studies of the periventricular zone reveal SST-immunoreactive innervation of SST-immunoreactive structures (Alonso et al., 1985). This observation led Alonso to suggest that SST may regulate its own secretion in the tuberoinfundibular system. This concept is supported by studies that demonstrated a decrease in SST secretion from hypothalamic explants and cultured neurons after exposure to SST (Peterfreund and Vale, 1984; Epelbaum et al., 1986) and a paradoxical increase of plasma GH after intraventricular injection of SST (Lumpkin et al., 1981; Murakami et al., 1987). We observed both SSTR 1 and SSTR2 in the medial parvicellular division of the paraventricular nucleus of the hypothalamus. Only SSTR1 was expressed in the anteroventral preoptic and anterior periventricular nuclei of the hypothalamus and in the anterior parvicellular division of the paraventricular nucleus of the hypothalamus (Fig. $6 B$ ). Future experiments injecting ligands specific for these SSTR forms into the periventricular hypothalamus, directed at blocking the secretion of SST, would be of considerable interest.

The primary source of GH-RH in the tuberoinfundibular system is the cells in the ventral and lateral portion of the arcuate nucleus of the hypothalamus (Swanson, 1987). Immunohistochemical studies at the light and ultrastructural level (Horvath ct al., 1989) suggestcd that these neurons share bidirectional connections with SST-immunoreactive neurons that are also located in the arcuate nucleus. Interestingly, dense hybridization of both SSTR1- and SSTR2-specific probes were observed in the ventrolateral arcuate nucleus, where GH-RH-immunoreactive neurons are observed in the rat brain (Fig. $3 A, B$ ), as well as in the dorsomedial portion of the nucleus. Immunohistochemical and in situ hybridization double-labeling experiments would be of considerable interest in determining whether SSTR 1 and SSTR2 are expressed in GH-RH-immunoreactive neurons. Dense levels of high-intensity SSTR I expression was also observed in the regions of the brain that project to the arcuate nucleus in the rat brain, such as the medial preoptic nucleus (Fig. 6A; see Simerly and Swanson, 1988), ventral subiculum (Fig. 4B; see Kohler, 1990), and to a lesser extent the bed nucleus of the stria terminalis (Swanson and Cowan, 1979). Our data suggest that SSTR1 and SSTR2 are present in multiple levels of the tuberoinfundibular axis as well as in the forebrain nuclei that project to this zone, implying that these receptors may be involved in the central integration of autonomic, behavioral, and neuroendocrine control.

Central autonomic regulation. Intraventricular infusions of SST-14 and -28 in the rat brain result in a pressor and bradycardic response that is thought to be primarily mediated by an elevation of peripheral levels of vasopressin (Brown, 1988; Rettig et al., 1989). Brown injected SST-28 into several forebrain regions involved in autonomic regulation as well as into the dorsal vagal complex. He concluded that the paraventricular nucleus was the locus of this pressor response, although the volume of the injections (500 nl) employed in this study would preclude precise localization of this effect. We observed SSIRI in several regions involved in regulation of the magnocellular secretory system, including the division of the paraventricular nucleus containing vasopressin-immunoreactive neurons in the mouse brain (C. D. Breder and C. B. Saper, unpublished observation) as well as forebrain nuclei that project to this region in the rat brain, such as the medial preoptic (Simerly and Swanson, 1988) and anteroventral periventricular (Standaert and Saper, 1988) nuclei and bed nucleus of the stria terminalis (Sawchenko and Swanson, 1983). We also observed SSTR2 expression in the internal lamina of the median eminence, the region of the infundibulum through which the axons of the magnocellular secretory system project to the posterior pituitary gland (Swanson, 1987). Interestingly, Brown (1988) observed a depressor effect after injection of SST-28 into the anterior hypothalamic area, which most likely would have included the medial preoptic nucleus, and also the central nucleus of the amygdala, where we observed SSTR 1 hybridization. Injections of smaller volumes of ligands specific for SSTR1 into these nuclei would be of considerable interest in examining the role of SST in central cardiovascular regulation.

Several cardiovascular and pulmonary responses have been described after intraparenchymal or intracisternal infusion of SST, to examine its effects in the dorsal vagal complex and ventral lateral medulla. Five hundred nanoliter injections of SST-28 into the nucleus of the solitary tract resulted in a depressor and bradycardic response (Koda et al., 1985; Brown, 1988). Expiratory apnea was induced after intracisternal SST14 infusion in the rat (Harfstrand et al., 1984). Jacquin et al. (1988) recorded intracellularly in neurons of the nucleus of the solitary tract of the rat and observed that application of SST14 and -28 hyperpolarized cells through the augmentation of 
$I_{\mathrm{M}}$, a voltage-dependent potassium current. Striking SSTR 1 hybridization was observed in the medial and commissural subnuclei of the nucleus of the solitary tract, which receives visceral sensory input from the cardiovascular and pulmonary systems (Loewy, 1990) and in the ventrolateral subnucleus, also known as the dorsal respiratory group because it contains neurons with inspiratory-related discharges (Smith et al., 1989). Yamamoto et al. (1986) applied SST to the ventral medullary surface of the cat brain and observed strong apnea with a complete cessation of phrenic nerve activity. Injections into the ventrolateral medulla resulted in an apneic and depressor response. Furthermore, Cunningham and Sawchenko (1989) described a dense SSTimmunoreactive projection from the nucleus of the solitary tract to the nucleus ambiguus. Sparse SSTR 1 and no SSTR2 hybridization was observed throughout these latter medullary structures. The possibility of an additional, yet uncharacterized SSTR in these latter regions involved in crucial roles in central autonomic function is certainly intriguing.

Complex, integrative function: cognition and polymodal sensory processing. SSTR 1 and SSTR2 were observed in structures such as the cortex, hippocampus, and basal and lateral nuclei of the amygdala, which are involved in complex, integrative activities (Figs. $2 A, B ; 3 A, B ; 5 A, B$ ). Previous studies have demonstrated SST-immunoreactive nerve fibers (Shimada and Ishikawa, 1989) and electrophysiological effects of SST (Watson and Pittman, 1988; Wang et al., 1989) in these regions. Both SSTR forms were observed in the claustrum (Fig. $3 A$ ), the vertical limb of the nucleus of the diagonal band, and the basal and lateral nuclei of the amygdala (Figs. $3 A, 4 A$ ), all of which share bidirectional projections with the cerebral cortex (Saper, 1987). SSTR 1 expression was also observed in regions that project diffusely to the cerebral cortex such as the magnocellular preoptic nucleus (Fig. 6.4), the lateral hypothalamic (Fig. 4A,B) and ventral tegmental areas (Fig. $7 A$ ), and the dorsal raphe, pedunculopontine, and medial parabrachial nuclei (Saper, 1987).

The distribution of SSTR 1 in the hippocampus is particularly intriguing (Fig. 5A,B). The septotemporal gradient of SSTR 1 in the hippocampus was similar in topography to the distribution of afferent projections from the medial septal and magnocellular preoptic nuclei and the nucleus of the diagonal band (Wyss et al., 1979; Gage et al., 1984; Saper, 1984), as well as the ventral and lateral part of the nucleus reuniens of the thalamus (Riley and Moore, 1981) and the dorsal raphe nucleus (Wyss et al., 1979 ) in the rat brain. The basal nuclei of the amygdala (Figs. $3 B, 4 A$ ), which expressed both SSTR forms, are reciprocally connected with several polymodal association areas, including the medial, orbital, and insular cortices, and portions of the hippocampal formation in the rat brain. It is therefore likely that SST may be active at multiple levels of the pathways influencing complex integrative function. Interestingly, each of the regions implicated in complex, integrative functions, and in which we observed SSTR 1 and SSTR2, demonstrates pathological changes in Alzheimer's disease (Saper, 1988).

\section{Different SSTR types}

Previous ligand binding (Patel et al., 1986; Reubi et al., 1987; Whitford et al., 1987; Matsumoto et al., 1991), analog crosslinking (Thermos et al., 1989; Patel et al., 1990), and physiological studies (Wang et al., 1989; Dichter et al., 1990) suggested that multiple SSTRs are present in the brain. Our data not only provide evidence for the expression of two distinct forms of SSTRs in the mouse brain but also suggest the existence of other forms. The ncuronal localization of SSTR1 and SSTR2 was indicated by their anatomical distribution and hybridization over thionin-stained cell bodies. Marin (1991) recently reported that SST potentiated $\alpha_{1}$-adrenergic activation of phospholipase $\mathrm{C}$ in astrocyte cultures. We did not observe diffuse hybridization, which would be expected if this cell type expressed SSTR 1 or SSTR2 (cf. McGrail et al., 1991; Watts et al., 1991). It is possible that astrocytes express another form of SSTR or are induced to express SSTR1 or SSTR2 in culture.

One of our most intriguing findings was the remarkably sparse hybridization in the striatum with both SSTR1 and SSTR2 probes, particularly in the caudate-putamen. This was surprising given previous reports on the high density of SST-immunoreactive fibers and terminals in the striatum (Chesselet and Graybiel, 1986), the profound effects of SSI on striatal second messenger systems (Markstein et al., 1989; Marin et al., 1991), and the high level of ['25I-Tyr" $]$-SST binding to striatal membranes (Srikant and Patel, 1981; Tran et al., 1985). Morphological analysis of striatal SST-immunoreactive neurons suggests that SSTRs would be localized in the extrastriosomal matrix (Chesselet and Graybiel, 1986), perhaps even functioning as autoreceptors on SST-immunoreactive cells. These data strongly suggest the existence of other SSTR subtypes in the mammalian brain.

\section{References}

Alonso G, Tapia-Arancibia L, Assenmacher I (1985) Electron microscopic immunocytochemical study of somatostatin neurons in the periventricular nucleus of the rat with special reference to their relationships with homologous neuronal processes. Neuroscience 16: 297-306.

Beal MF, Mazurek MF, Svendsen CN, Bird ED, Martin JB (1986) Widespread reduction of somatostatin-like immunoreactivity in the cerebral cortex in Alzheimer's disease. Ann Neurol 20:489-495.

Benoit R, Ling N, Alford B, Guillemin R (1982) Seven peptides derived from prosomatostatin in rat brain. Biochem Biophys Res Commun 107:944-950.

Berman AL (1968) In: The brainstem of the cat: a cytoarchitectonic atlas with stereotaxic coordinates, $p$ 175. Madison: University of Wisconsin.

Brazeau P, Vale W, Burgus R, Ling N, Butcher M, Guillemin R (1973) Hypothalamic polypeptide that inhibits the secretion of immunoreactive pituitary growth hormone. Science 179:77-79.

Brown MR (1988) Somatostatin-28 effects on the central nervous system regulation of vasopressin secretion and blood pressure. Neuroendocrinology 47:556-562.

Cechetto DF, Saper CB (1987) Evidence for a viscerotopic sensory representation in the cortex and thalamus in the rat. J Comp Neurol 262:27-45.

Chesselet MF, Graybiel AM (1986) Striatal neurons expressing somatostatin immunoreactivity: evidence for a peptidergic interneuronal system in the cat. Neuroscience 17:547-571.

Cunningham ET, Sawchenko PE (1989) A circumscribed projection from the nucleus of the solitary tract to the nucleus ambiguus in the rat: anatomical evidence for somatostatin-28-immunoreactive interneurons subserving reflex control of esophageal motility. J Neurosci 9:1668-1682.

Danguir J (1986) Intracerebroventricular infusion of somatostatin selectively increases paradoxical sleep in rats. Brain Res 367:26-30.

Dawbarn D, Rossor MN, Mountjoy CQ, Roth M, Emson PC (1986) Decreased somatostatin immunoreactivity but not neuropeptide $Y$ immunoreactivity in cerebral cortex in senile dementia of Alzheimer type. Neurosci Lett 70:154-159.

Dichter MA, Wang H-L, Reisine T (1990) Electrophysiological effects of somatostatin-14 and somatostatin-28 on mammalian central nervous system neurons. Metabolism 39[Suppl 2]:86-90.

Epelbaum J, Dussaillant M, A Enjalbart, Kordon C, Rostene W (1985) Autoradiographic localization of a non-reducible somatostatin analog 
(25I-CGP-23996) binding sites in the rat brain: comparison with membrane binding. Peptides 6:713-719.

Epelbaum J, Tapia-Arancibia L, Alonso G, Astier H, Kordon C (1986) The anterior periventricular hypothalamus is the site of somatostatin inhibition on its own release: an in vitro and immunohistochemical study. Neuroendocrinology 44:255-259.

Fulwiler CE, Saper CB (1984) Subnuclear organization of the efferent connections of the parabrachial nucleus in the rat. Brain Res Rev 7: 229-259.

Gage FH, Bjorklund A, Stenevi U (1984) Cells of origin of the ventral cholinergic septohippocampal pathway undergoing compensatory collateral sprouting following fimbria-fornix transection. Neurosci Lett 44:211-216.

Harfstrand A, Kalia M, Fuxe K, Kaijser L, Agnati LF (1984) Somatostatin-induced apnea: interaction with hypoxia and hypercapnia in the rat. Neurosci Lett 50:37-42.

Hemmendinger LM, Moore RY (1984) Interpeduncular nucleus organization in the rat: cytoarchitecture and histochemical analysis. Brain Res Bull 13:163-179.

Herbert H, Moga MM, Saper CB (1990) Connections of the parabrachial nuclcus with the nuclcus of the solitary tract and the medullary reticular formation in the rat. J Comp Neurol 293:540-580.

Horvath S, Palkovitz M, Gorcs T, Arimura A (1989) Electron microscopic immunohistochemical evidence for the existence of bidirectional synaptic connections between growth hormone-releasing hormone and somatostatin-containing neurons in the hypothalamus of the rat. Brain Res 481:8-15.

Ipp E, Rivier J, Dobbs RE, Brown M, Vale W, Unger RH (1979) Somatostatin analogues inhibit somatostatin release. Endocrinology 104:1270-1273.

Jacquin T, Champagnat J, Madamba S, Denavit-Saubie M, Siggins GR (1988) Somatostatin depresses excitability in neurons of the solitary tract complex through hyperpolarization and augmentation of $I_{\mathrm{M}}$, a non-inactivating voltage-dependent outward current blocked by muscarinic agonists. Proc Natl Acad Sci USA 85:948-952.

Johansson O, Hokfelt T, Elde RP (1984) Immunohistochemical distribution of somatostatin-like immunoreactivity in the central nervous system of the adult rat. Neuroscience 13:265-339.

Kentroti S, Vernadakis A (1990) Growth hormone-releasing hormone and somatostatin influence neuronal expression in developing chick brain. II. Cholinergic neurons. Brain Res 512:297-303.

Kimura N (1989) Developmental change and molecular properties of somatostatin receptors in the rat cerebral cortex. Biochem Biophys Res Commun 160:72-78.

Koda LY, Ling N, Benoit R, Madamba SG, Bakhit C (1985) Blood pressure following microinjection of somatostatin related peptides into the rat nucleus tractus solitarii. Eur J Pharmacol 113:425-430.

Kohler C (1990) Subicular projections to the hypothalamus and brainstem-some novel aspects revealed in the rat by the anterograde Phaseolus vulgaris leukoagglutinin (PHA-L) tracing method. In: Progress in brain research, Vol 5, Understanding the brain through the hippocampus (Storm-Mathisen J, Zimmer J, Ottersen OP, eds), pp 59-69. Amsterdam: Elsevier.

LeDoux JE, Ruggiero DA, Reis DJ (1985) Projections to the subcortical forebrain from anatomically defined regions of the medial geniculate body in the rat. J Comp Neurol 242:182-213.

Leroux P, Quirion R, Pelletier G (1985) Localization and characterization of brain somatostatin receptors as studied with somatostatin14 and somatostatin-28 receptor autoradiography. Brain Res 347:74 84.

Leroux P, Gonzalez B, Bucharles C, Vaudry H (1991) Autoradiography of somatostatin receptors in rat cerebellum. Methods Neurosci 5:538-553.

Lin MT, Chen JJ, Ho LT (1987) Hypothalamic involvement in the hyperglycemia and satiety action of somatostatin in rats. Neuroendocrinology 45:62-67.

Loewy AD (1990) Central autonomic pathways. In: Central regulation of autonomic functions (Loewy AD, Spyer KM, eds), pp 88-103. New York: Oxford UP.

Lumpkin MD, Negro-Vilar A, McCann SM (1981) Paradoxical elevation of growth hormone by intraventricular somatostatin: possible ultrashort-loop feedback. Science 211:1072-1073.

Marin P, Delumeau JC, Tence M, Cordier J, Glowinski J, Premont J (1991) Somatostatin potentiates the alphal-adrenergic activation of phospholipase-C in striatal astrocytes through a mechanism involving arachidonic acid and glutamate. Proc Natl Acad Sci USA 88:90169020.

Markstein R, Stockli KA, Reubi JC (1989) Differential effects of somatostatin on adenylate cyclase as functional correlate for different brain somatostatin receptor subpopulations. Neurosci Lett 104:1318.

Marshall PE, Landis DMD (1985) Huntington's disease is accompanied by changes in the distribution of somatostatin-containing neuronal processes. Brain Res 329:71-82.

Martin JL, Chesselet MF, Raynor K, Gonzales C, Reisine T (1991) Differential distribution of somatostatin receptor subtypes in rat brain revealed by newly developed somatostatin analogs. Neuroscience 41 : 581-593.

Matsumoto A, Arai Y, Urano A, Hyodo A (1991) Cellular localization of gap junction messenger RNA in the neonatal rat brain. Neurosci Lett 124:225-228.

McGrail KM, Phillips JM, Sweadner KJ (1991) Immunofluorescent localization of three Na,K-ATPase isozymes in the rat central nervous system - both neurons and glia can express more than one $\mathrm{Na}, \mathrm{K}$ ATPase. J Neurosci 11:381-391.

Merchenthaler I, Setalo G, Csontos C, Petrusz P, Flerko B, Negro-Vilar A (1989) Combined retrograde tracing and immunocytochemical identification of luteinizing hormone-releasing hormone and somatostatin-containing neurons projecting to the median eminence in the rat. Endocrinology 125:2812-2821.

Murakami Y, Kato Y, Kabayama Y, Inoue T, Koshiyama H, Imura H (1987) Involvement of hypothalamic growth hormone (GH)-releasing factor in $\mathrm{GH}$ secretion induced by intracerebroventricular injection of somatostatin in rats. Endocrinology 120:311-316.

Nabekura J, Mizuno Y, Oomura Y (1989) Inhibitory effects of somatostatin on vagal motoneurons in the brainstem of the rat. Am J Physiol 256:C155-C159.

Obata-Tsuto HL (1987) Light and electron microscopic study of somatostatin-like immunoreactive neurons in the rat hippocampus. Brain Res Bull 18:613-620.

Olszewski J (1960) On the anatomical and functional organization of the spinal trigeminal nucleus. J Comp Neurol 92:401-413.

Patel, YC, Baquiran G, Srikant CB, Posner BI (1986) Quantitative in vivo autoradiographic localization of [125I-Tyr11] somatostatin-14and [Leu8,D-Trp22-125I-Tyr25] somatostatin-28-binding sites in the rat brain. Endocrinology 119:2262-2269.

Patel YC, Murthy KK, Escher E, Banville D, Spiess J, Srikant CB (1990) Mechanism of action of somatostatin: an overview of receptor function and studies of molecular characterization of purification of somatostatin receptor proteins. Metabolism 9[Suppl 2]:63-69.

Peterfreund RA, Vale WW (1984) Somatostatin analogues inhibit somatostatin secretion from cultured hypothalamus cells. Neuroendocrinology 39:397-402.

Price, JL, Russchen FT, Amaral DG (1987) The limbic region. II. The amygdaloid complex. In: Handbook of chemical neuroanatomy (Bjorklund A, Hokfelt T, Swanson LW, eds), pp 279-388. Amsterdam: Elsevier.

Rens-Domiano S, Law SF, Yamada Y, Seino M, Bell GI, Reisine T (1992) Pharmacological properties of two cloned somatostatin receptors. Mol Pharmacol, in press.

Rettig R, Geist R, Sauer U, Rohmeiss P, Unger T (1989) Central effects of somatostatin: pressor response, AVP release, and sympathoinhibition. Am J Physiol 257:R588-R594.

Reubi JC, Probst A, Cortes R, Palacios JM (1987) Distinct topographical localization of two somatostatin receptor subpopulations in the human cortex. Brain Res 406:391-396.

Riley JN, Moore RY (1981) Diencephalic and brainstem afferents to the hippocampal formation of the rat. Brain Res Bull 6:437-444.

Sambrook J, Fritsch EF, Maniatis T (1989) Molecular cloning: a laboratory manual. Cold Spring Harbor, NY: Cold Spring Harbor Laboratory.

Saper CB (1982) Convergence of autonomic and limbic connections in the insular cortex of the rat. J Comp Neurol 210:163-173.

Saper CB (1984) Organization of cerebral cortical afferent systems in the rat. I. Magnocellular basal nucleus. J Comp Neurol 222:313-342.

Saper CB (1987) Diffuse cortical projection systems: anatomical organization and role in cortical function. In: Handbook of physiology, Vol V, The nervous system (Plum F, ed), pp 169-210. Bethesda: American Physiological Society.

Saper CB (1988) Chemical neuroanatomy of Alzheimer's disease. In: 
Handbook of psychopharmacology, Vol 20, Biology of Alzheimer's disease (Iversen SD, Iversen LL, Snyder SH, eds), pp 131-156. New York: Plenum.

Saper CB, Reis D, Joh T (1983) Mcdullary catecholamine imputs to the anteroventral third ventricular cardiovascular regulatory region in the rat. Neurosci Lett 42:285-291.

Saper CB, Swanson LW, Cowan WM (1976) The efferent connections of the ventromedial nucleus of the hypothalamus of the rat. J Comp Neurol 169:409-442.

Sawchenko PE, Swanson LW (1983) The organization of forebrain afferents to the paraventricular and supraoptic nuclei of the rat. J Comp Neurol 218:121-144.

Scalia $F$ (1972) The termination of retinal axons in the pretectal region of mammals. J Comp Neurol 145:223-258.

Shimada O, Ishikawa H (1989) Somatostatin-containing neurons in the mouse brain: an immunohistochemical study and comparison with the rat brain. Arch Histol Cytol 52:201-212.

Simcrly RB, Swanson LW (1988) Projections of the medial preoptic nucleus: a Phaseolus vulgaris leucoagglutinin anterograde tract-tracing study in the rat. J Comp Neurol 270:209-242.

Simmons DM, Arriza JL, Swanson LW (1989) A complete protocol for in situ hybridization of messenger RNAs in brain and other tissues with radiolabeled single-stranded RNA probes. J Histotechnol 12: 169-181.

Smith JC, Morrison DE, Ellenberger HH, Otto MR, Feldman JL (1989) Brainstem projections to the major respiratory neuron populations in the medulla of the cat. J Comp Neurol 281:69-96.

Srikant CB, Patel YC (1981) Somatostatin receptors: identification and characterization in rat membranes. Proc Natl Acad Sci USA 78: 3930-3934.

Standaert DG, Saper CB (1988) Origin of the atriopeptin-like immunoreactive innervation of the paraventricular nucleus of the hypothalamus. J Neurosci 8:1940-1950.

Swanson LW (1987) The hypothalamus. In: Handbook of chemical neuroanatomy (Bjorklund A, Hokfelt T, Swanson LW, eds), pp l124. Amsterdam: Elsevier.

Swanson LW, Cowan WM (1979) The connections of the septal region in the rat. J Comp Neurol 186:621-656.

Swanson LW, Cowan WM, Jones EG (1974) An autoradiographic study of the efferent connections of the ventral lateral geniculate nucleus in the rat. J Comp Neurol 156:143-164.

Taber E, Brodal A, Walberg F (1960) The raphe nuclei of the brainstem in the cat. I. Normal topography and cytoarchitecture and general discussion. J Comp Neurol 114:161-188.

Thermos K, He H-T, Wang H-L, Margolis N, Reisine N (1989) Bio- chemical properties of brain somatostatin receptors. Neuroscience 31:131-141.

Tran VT, Beal MF, Martin JB (1985) Two types of somatostatin receptors differentiated by cyclic somatostatin analogues. Science 228 : 492-494.

Uhl GR, Tran V, Snyder SH, Martin JB (1985) Somatostatin receptors: distribution in rat central nervous system and human frontal cortex. J Comp Neurol 240:288-304.

Unger JW, McNeill TH, Lapham LL, Hamill RW (1988) Neuropeptides and neuropathology in the amygdala in Alzheimer's disease: relationship between somatostatin, neuropeptide $\mathrm{Y}$ and subregional distribution of neuritic plaques. Brain Res 452:293-302.

Villar MJ, Hokfelt T, Brown JC (1989) Somatostatin expression in the cerebellar cortex during postnatal development. Anat Embryol 179:257-267.

Vincent SR, McIntosh CHS, Buchan AMJ, Brown JC (1985) Central somatostatin systems revealed with monoclonal antibodies. J Comp Neurol 238:169-186.

Wang H-L, Bogen C, Reisine T, Dichter M (i989) Somatostatin-14 and somatostatin-28 induce opposite effects on potassium currents in rat neocortical neurons. Proc Natl Acad Sci USA 86:9616-9620.

Watson TWJ, Pittman QJ (1988) Somatostatin (14) and -(28) but not somatostatin (1-12) hyperpolarize CAl pyramidal neurons in vitro. Brain Res 448:40-45.

Watts AG, Sanchez-Watts G, Emanuel JR, Levenson R (1991) Cellspecific expression of messenger RNAs encoding $\mathrm{Na}+, \mathrm{K}+-$-ATPase alpha-subunit and beta-subunit isoforms within the rat central nervous system. Proc Natl Acad Sci USA 88:7425-7429.

Wcightman DR, Whitford C, Snell C, Hirst B, Brundish DE, KendallTaylor PA (1985) Rat brain membranes possess two high-affinity binding sites for ${ }^{3} \mathrm{H}$-somatostatin. Neurosci Lett 55:161-166.

Whitford C, Candy JM, Snell C, Hirst B, Oakley AE, Johnson M, Thompson JE (1987) Autoradiographic visualization of binding sites for $\left[{ }^{3} \mathrm{H}\right]$ somatostatin in the rat brain. Eur J Pharmacol 138:327-333.

Wyss JM, Swanson LW, Cowan WM (1979) A study of subcortical afferents to the hippocampal formation in the rat. Neuroscience 4 : $463-476$.

Yamada Y, Post SR, Wang K, Tager HS, Bell GI, Seino S (1992) Cloning and functional expression of a family of human and mouse somatostatin receptors expressed in brain, gastrointestinal tract and kidney. Proc Natl Acad Sci USA 89:251-255.

Yamamoto Y, Runold M, Prabhako N, Pantaleo T, Lagercrantz H (1988) Somatostatin in the control of respiration. Acta Physiol Scand 194:529-533.

Zilles K (1985) The cortex of the rat, pp 1-111. Heidelberg: Springer. 